\title{
Guanaco management by pastoralists in the Southern Andes
}

\author{
Gabriela Lichtenstein $^{{ }^{*}}$ and Pablo D Carmanchahi ${ }^{2}$
}

\footnotetext{
* Correspondence: lichtenstein.g@ gmail.com

${ }^{1}$ Instituto Nacional de Antropología y Pensamiento Latinoamericano (INAPL), CONICET, 3 de Febrero 1378, 1426 Buenos Aires, Argentina Full list of author information is available at the end of the article
}

\begin{abstract}
Background: As with most wild ungulates, guanacos (Lama guanicoe) overlap their range with domestic livestock resulting in a conflict for the use of rangelands between local livelihoods and conservation. This article explores a multiple-objective project that was set up in the La Payunia Provincial Reserve (Mendoza, Argentina) in order to address conservation of a migratory population of guanacos; desertification processes; and poverty alleviation. This study analyses the potential for guanaco use and management by a low-income Cooperative, the socio-economic impacts derived from the use, and the challenges facing the experience.

Results: The Cooperative Payún Matrú was formed in 2005 mainly by local goat herders with a subsistence economy, thus providing a unique example where the beneficiaries of guanaco use are a low-income community. The project was successful in articulating the agendas of several stakeholders. A model for guanaco use under high animal welfare standards was developed as well as an alternative source of income for local people.

Conclusions: The case study illustrates how a conflict over the use of grassland between domestic livestock and a wild species could be turned into an opportunity for economic diversification for pastoralists. Lessons are drawn that could contribute to policy decisions as well as sustainable use programmes for other wildlife species.
\end{abstract}

Keywords: Patagonia, Sustainable use, Guanacos, Luxury fibres, Poverty alleviation, Live shearing

\section{Background}

Pastoralism refers to any predominantly livestock-based production system that is mainly extensive in nature and uses some form of mobility of domestic livestock (Hatfield and Jonathan 2006). This natural resource management system is an adaptation to marginal environments, characterized by climatic uncertainty and low-grade resources. To reduce risks and maximize the productivity of variable and widely dispersed resources, local communities depend upon flexibility (through seasonal mobility, temporary rangeland exploitation and herd diversification) and social capital (within and between pastoralists and other groups) to ensure access to resources (Nori et al. 2005).

In many societies, pastoral communities remain among the most politically and economically marginalized of groups. Customary rangelands and migratory transit routes are shrinking in the face of spreading cultivations, intensive cattle production, mining, oil extraction, land privatization, protected areas and impermeable international borders. Herds

(c) 2012 Lichtenstein and Carmanchahi; licensee Springer. This is an Open Access article distributed under the terms of the Creative Commons Attribution License (http://creativecommons.org/licenses/by/2.0), which permits unrestricted use, distribution, and reproduction in any medium, provided the original work is properly cited. 
are threatened by climate change, lengthy droughts and desertification. Traditional local livelihoods are at risk as pastoralists face insecurity over land and resource tenure, inadequate provision of public services, poor infrastructure, lack of communication and distance to markets, among other challenges (Naumann and Madariaga 2003; Nori et al. 2005).

In general, South American pastoralism is confined nowadays to elevations above $3700 \mathrm{~m}$ in the Puna and Altiplano high Andean ecoregions in South and Central Peru, the West of Bolivia, the North of Chile and the North-West of Argentina (Westreicher et al. 2007). The activity of pastoralists is also important in the Patagonian Andes of Argentina, from the South of Mendoza to Chubut Province. In these areas, 7,500 crianceros practice either sedentary or transhumant pastoralism (Bendini et al. 2010). Mean herd size (including sheep, goats and sometimes cows) is approximately 1,000 animal units as sheep equivalent, and modal size is $250-500$ (Bendini et al. 2010).

According to the archaeological records, local populations from Western Patagonia were hunter gatherers and later became transhumant herders, moving with their herds between the present territory of Argentina and Chile (Bandieri et al. 1993). The movements between the winter and summer settlements across the Andes predate the introduction of domestic livestock around the seventeenth century and continued until the international border between the two countries was finally closed in 1941 (Lanari 2004).

At the end of the nineteenth century, the Argentinean government launched a military campaign in Patagonia with the aim of expanding the economic frontier. The socalled "Desert Campaign" resulted in thousands of indigenous people killed and communities exterminated while vast tracts of land were converted into massive ranches for the production of sheep's wool for export to Europe. Fences and wires started dividing the territory and restricting the movement of people and animals. Within 50 years of the introduction of sheep in Patagonia, their numbers peaked at 22 million (Aagensen 2000). Since the "Desert Campaign", several factors have contributed to desertification in Patagonia such as too high stocking rates, overgrazing, inadequate use of natural grasslands; lack of training and advisory services for producers; poor transference of management technologies adapted for arid areas; low value of primary production; overestimation of grazing fields receptivity; commercialization difficulties and limited productive alternatives due to the harsh environment (e.g. Paruelo et al. 2006).

The massive introduction of domestic sheep affected the numbers and distribution of guanacos, the most important native herbivore of these arid areas. The guanaco is one of four South American camelid species. The others are the vicuña (Vicugna vicugna), llama (Lama glama) and alpaca (Vicugna pacos). Guanaco populations declined after the introduction of domestic sheep in Patagonia, and with the emerging conflicts with sheep breeders and their livestock competing for food and water. Conflicts with sheep ranching, poaching, habitat degradation due to overgrazing, legal overhunting and lack of sound management schemes further contributed to the demise of guanacos. Today, the guanaco occupies only $40 \%$ of its original range (Puig 1995). Although the species is not threatened with demographic extinction on a continental scale, it is ecologically extinct in most of its remaining range (Novaro et al. 2000).

Guanacos were included in CITES Appendix II in 1978. The negative perception of guanacos by sheep ranchers, added to the strong European demand for guanaco fibre and calf fleeces resulted in major exports of guanaco fleeces, and the issue of large numbers of permits to kill guanacos (Baldi et al. 2010). In 1993, CITES Standing 
Committee recommended that all Parties suspend imports of specimens of guanacos from Argentina until the biological basis for its management program and its mechanisms for controlling trade were specified. This recommendation fostered the creation of a Guanaco National Management Plan in 2006 in order to ensure the sustainability of management activities. Argentinean legislation only allows exportation of guanaco fibre harvested from live individuals.

Guanacos and vicuñas share a very peculiar feature: an extremely fine fibre that can be obtained through live shearing without the need of killing the individuals thus provides a novel example for sustainable wildlife use. These wild camelids were recognized by FAO as key species for Latin America rural development, due to their economic value, the demand for their products and the potential to generate employment sources. Given that guanacos are low impact grazers, they could play a fundamental role to stop desertification processes in arid ecosystems, relieve pressure on native habitat and even facilitate limited range recovery while providing an economic alternative to local producers (FAO 1992).

Vicuña and guanaco management programmes are a variation on what are collectively referred to as community-based natural resource management initiatives, a form of natural resource management that emerged as a strategy linking conservation and community development through local participation and sustainable use. The objective is to deliver a financial return to local communities that protect and have protected the species on their land for decades and have potentially foregone other income because of the presence of wild camelids. The hope is that rather than continuing being antagonistic towards wild camelids, rural residents would assist government efforts in monitoring and protecting the species. Getting local people involved in conservation is the only viable option to decrease conflict with domestic livestock and for an effective human stewardship in the vast areas inhabited by these species (Lichtenstein 2011).

The guanaco live-shearing model started during the late 1990s when several large sheep ranches in Argentina began managing guanacos by conducting live capture and shearing and thereby producing fibre for export. Since 2002, the capture, shearing and release of guanacos to sell their fibre increased in Patagonia, with thousands of guanacos shorn every year (Baldi et al. 2010). The initial high market value (USD \$150) of guanaco fibre influenced landowners to invest in management infrastructure. Low sheep wool prices also contributed to rancher's interest in exploring economic alternatives (Von Thüngen et al. 2010). By 2010, most of the projects had stopped operating due to difficulty in marketing guanaco, the decrease in market price to USD \$40-60 per kilo and the relative increase in sheep wool price. As in the case of vicuña, there are only two trade companies that buy raw fibre that is exported mainly to Italy, and control market prices (Lichtenstein 2011).

Since 2005, the Cooperative Payún Matrú has developed methodologies to capture, shear and release wild guanacos working with high animal welfare standards in Mendoza Province, Argentina. This Cooperative is composed mainly by local pastoralists with a subsistence economy, thus providing a unique example where the beneficiaries of guanaco use are the members of a low-income community that live in and near a Protected Area. From the start of the project, the Cooperative decided to add value to the raw fibre in order to increase the revenues and generate new sources of employment.

This article explores the potential for guanaco management by a low-income Cooperative in a Protected Area; identifies the main stakeholders and their interests in the project; describes the guanaco management system, and the capture and fibre harvesting activities; 
reports fibre yields; describes the marketing system; and develops some recommendations for the future development of the project. Lessons are thus drawn that could contribute to policy decisions as well as to sustainable use programs for other wildlife species.

\section{Study area and the guanaco population}

The research was undertaken in La Payunia Provincial Reserve, located in the Malargüe Department, in the South of the Mendoza province in Argentina (between S36 $06^{\circ}$ 'W68 34' and S36 $36^{\prime}$ 'W69'23'; Figure 1). The Reserve covers approximately $6540 \mathrm{~km}^{2}$ of state-owned and private lands. The climate is typically continental desert with average temperatures of $6^{\circ} \mathrm{C}$ in winter and $20^{\circ} \mathrm{C}$ in summer, and $255 \mathrm{~mm}$ of average annual

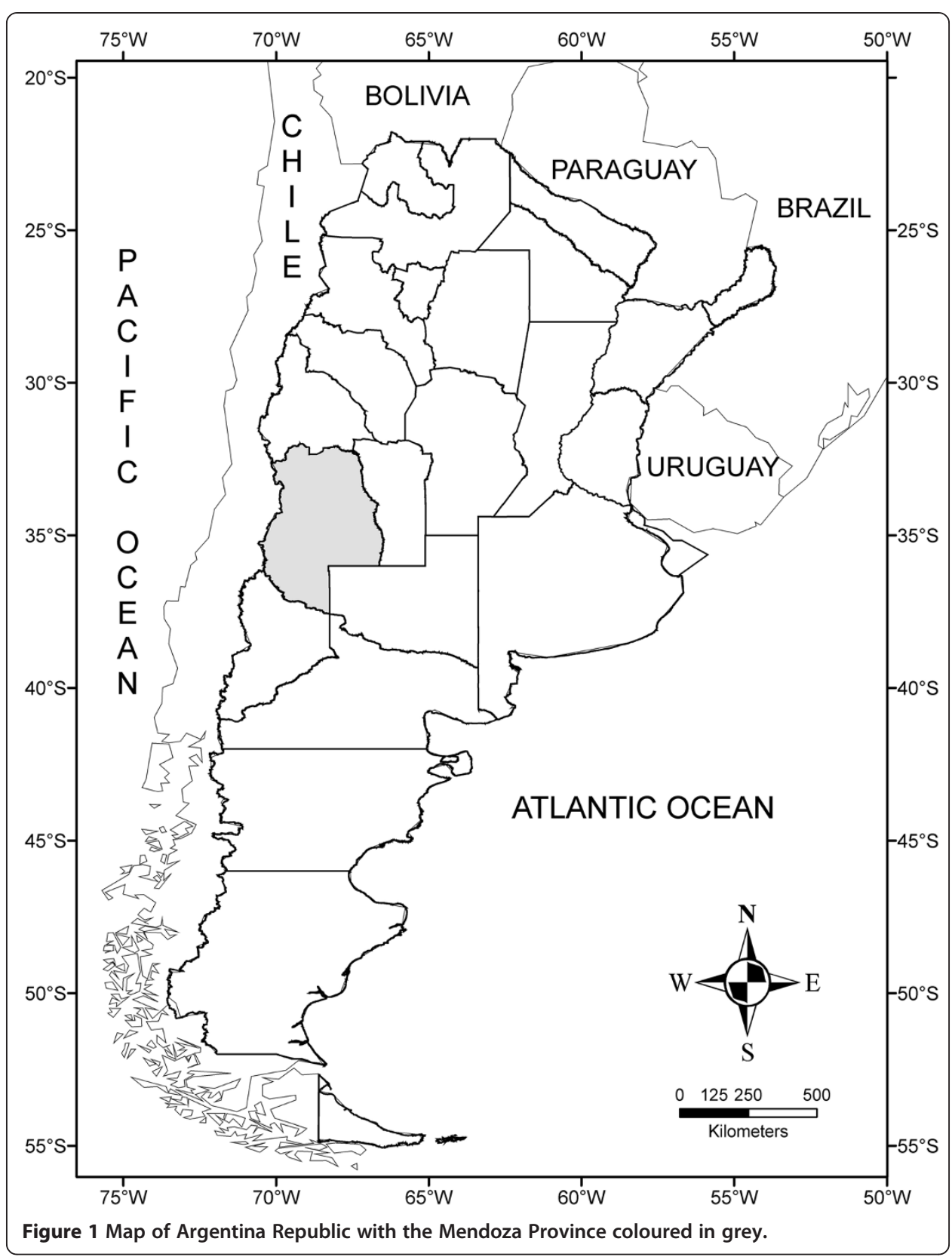


rainfall. The semiarid biome dominates this region and is included in La Payunia Phytogeographic Province within the Andean-Patagonian domain (Martínez Carretero 2004).

The region has no permanent superficial water bodies and groundwater is scarce. In the wet season, water supplied by rain and snow are accumulated in depressions on the ground forming temporary lagoons (Candia et al. 1993). Intensive agricultural activities are unlikely due to the poor and sandy soil.

The gradual decline in the guanaco population of the Reserve was due particularly to intense illegal hunting during the decade of the 1960s and 1970s. This pressure resulted in a reduction of the guanaco's distribution, even in areas where the presence of this camelid had been very significant (Puig et al. 2003). In 1982, The Payunia Provincial Reserve was created in order to preserve the rich flora, fauna, archaeological and scenic beauty of the area. As in the case of other Protected Areas created during that period, the participation of local people in the design and establishment of the Reserve was very limited. Livestock was allowed to remain in the Protected Area grazing outside the Intangible Zone (Candia et al. 1993).

Since the creation of the Reserve, the guanaco population has started to increase, mainly due to the prevention of poaching and to management measures for the conservation of the species and its habitat. Nowadays, the area supports the largest migratory guanaco population in the central region of Argentina, with more than 10,000 individuals (Candia et al. 1993). The number of guanacos in La Payunia has grown continuously by an average of $2 \%$ per year during the last 20 years, since the reserve was established (Puig et al. 2003).

\section{Socioeconomic context}

Due to the harsh living conditions, limited amenities and lack of basic services such as access to water, sanitation and electricity, health facilities, as well as remoteness from markets and schools, the Reserve is sparsely populated with about 150 people living in 42 family groups. These families are widely dispersed and separated from each other. Productive activities were originally based on sheep farming, but as land degradation increased, sheep were replaced by goats which are more successful in marginal areas. Local economies are mainly based on selling both young goats (chivitos or kids) and old goats for meat. Given the isolation of most homesteads, producers sell their production individually to middlemen or barter for food (sugar, flour, mate tea). Most of the crianceros live on public lands or on a homestead within a large private property where they pay an annual "rent" to the landowner in the form of kids. Some crianceros who live in areas of better pastures of the Reserve also own a few cows and sheep (Fernández 2004).

Producers raise mostly goats of the Creole race given its adaptation to the harsh environmental conditions prevalent in the area, and, to a lesser extent, Anglo Nubian, Cashmere and Angora races. As a result of these crosses, there is heterogeneity of animals resulting in very low quality products (Macario et al. 2007). Goats are managed extensively on natural grasses and receive no food supplement during the periods of low primary productivity. Continuous grazing results in land degradation and loss of plant cover. Management results in spontaneous abortions and weak kids that are unable to feed due to low milk production and low herd productivity. Goats are sold or bartered locally in adverse conditions (Macario et al. 2007). 
During the summer season (November to March), the producers located in the West of the Reserve move with their herds to the Andean foothills, while the residents that live in the Eastern side and closer to good feeding grounds remain sedentary. The work of goat husbandry is performed by the family group with a division of labour; men are responsible for tending the herd, including shearing, while women perform housework, feed the animals and care for the kids. Economic activities are mostly individual due to the long distance between settlements. A recent economic activity in the region is the hiring of young people by oil and mining companies. This contributes to a strong outmigration from rural areas to large urban centres producing a gradual depopulation of rural areas.

\section{Guanaco fibre}

Guanaco fibre is amongst the finest animal fibres. It belongs to the specialty or superfine fibre category together with cashmere, angora, camel hair, alpaca and vicuña. Guanaco fibre is not on average as fine as that of the vicuña but otherwise quite similar in its thermal properties, softness, colour variations of brown and the presence of guard hair. According to fibre experts, these two fibres are very difficult to distinguish even with a microscope. However, whereas wearing a vicuña garment is "a status symbol", guanaco fibre is not widely known (Lichtenstein 2011).

Guanacos have a double coat fleece similar to that of cashmere. The under coat, which is referred to as the down hair, is a fine fibre that ranges in colour from honey brown to dark cinnamon. The outer coat consists of coarse fibres called guard hairs which are a darker brown and help to keep debris and moisture out. Fleece refers to the whole pelage of the animal including the down hair and guard hairs, and its weight reaches 300-700 g per individual (Quispe et al. 2009). Fibre diameter is a key factor in determining the potential economic value of fibre produced. Fibre diameter is $14-17 \mu \mathrm{m}$ for adult guanacos. Fibre length is the measurement that interests spinners as much as micron counts, as the longer the fibre, the finer it can be spun. Guanaco fibre has an average length of about $3 \mathrm{~cm}$, which is on the shorter end of the fibre length spectrum (Quispe et al. 2009).

\section{Results and discussion}

\section{Project background}

In 2005, representatives of 11 families living within the La Payunia Reserve and its influence zone organized themselves to form the Payún Matrú Cooperative. The goal of the Cooperative was to develop a global market for luxury guanaco fibre and yarn which would in turn provide long-term employment for the people of La Payunia area and greater income for the population so that livelihoods could be improved. The Cooperative was also aimed at preserving the local culture and encouraging young people in particular to remain in La Payunia area rather than leaving for the nearby cities.

As time went on, the Cooperative activities became more diversified and members started working on three different projects: (1) the production and processing of guanaco and cashmere; (2) community tourism and (3) revegetation with native plant species of land degraded by oil production as a mitigation measure of damage and environmental restoration.

To carry out this latter activity, the Cooperative built a nursery for native plants generated from seeds collected in the same place where rehabilitation is performed. New 
pastures are generated for native wildlife and livestock. The revegetation of unused roads constructed by oil companies during the exploration phase also impedes the movement of poachers and rustlers in the interior of the Reserve.

At present, the Cooperative has 17 members that represent 71 direct beneficiaries. The Cooperative is a jointly owned commercial enterprise that produces goods and services and is run for the benefit of its owners. The compensation model of the Cooperative consists of an equal distribution of profits among the members. When members directly work on a specific project, they are compensated with a daily wage.

The project was very successful in articulating the agendas of several stakeholders:

1. The Cooperative: Main beneficiaries, particularly keen to generate alternative sources of income.

2. Provincial Department of Renewable Natural Resources: Authorities in charge of law enforcement in Natural Protected Areas and related to wildlife. They saw the project as a way of creating incentives for local people to accept and help enforce the Payunia Protected Area and contribute towards guanaco conservation.

3. Municipality of Malargüe: Public department in charge of socio-productive development of the region. This was a key stakeholder at the beginning of the project. The project was aligned with their aim of generating alternative sources of income to local producers and getting local political support.

4. International NGOS and IUCN's South American Camelid Specialist Group: Saw the project as a means to improve conservation of wildlife and habitats and to develop a sustainable use model.

5. Applied scientists: Interested in developing a protocol to minimize stress in guanaco captures, and generate long-term data on the biological and social impacts of using guanacos as a strategy for species and arid land conservation and rural development.

As the project developed, new collaborations were either permanently or temporarily developed from international to the local level (e.g. Sustainable Communities International Foundation, Ministry of Science and Technology (Mincyt), National Institute of Industrial Technology (INTI), Ministry of Labour, etc.). The ability of the Cooperative to collaborate with multiple partners contributed towards the project resilience and created a safety net. The collaborations also entitled Cooperative members to become more visible (e.g. participating in conferences, meeting Ministers, etc.), increase their negotiating power with potential clients and become more empowered.

\section{Management activities}

Given that guanaco management activities take place in a Protected Area, the Provincial Department of Natural Resources requires the Cooperative to present an environmental impact statement every 2 years. The project is audited by scientific, academic and technical agencies that evaluate its environmental and socio-economic impact, and is scrutinized by local protectionist NGOs that are practically able to stop the activity if they consider that guanacos are not properly managed.

The trap, corrals and the entire infrastructure related to handling of the guanaco have to be installed every season and removed after shearing in order to minimize their environmental impact. Surveys are made to study the guanaco populations before and 
after the round-up to determine possible effects of this activity on demographic parameters and to determine whether there is animal mortality associated with shearing. During the shearing, body condition of each captured guanaco is also monitored by specialized wildlife veterinarians. Biological samples are taken and behavioural responses recorded in order to determine the physiological and behavioural effect of this activity.

The round-up is not only an economic activity for the Cooperative members, but also a social and cultural event and an opportunity to meet and share experiences with a variety of people. This is particularly appreciated by the rural residents that live in very isolated environment. The round-ups are attended by primary and high school rural students that learn about their natural environment; university students, researchers and wildlife veterinarians that make use of the opportunity to get data from a wild species; park rangers that use the experience as a part of their training; guanaco producers and Cooperative members from other regions or provinces that are keen to replicate the experience; fibre experts, international NGOs and technicians from different public agencies, etc. Inspectors from the Provincial Department of Renewable Natural Resources oversee the capture and shearing to make sure that it minimizes the impact on the species and to certify the legal origin of the fibre. The animal welfare standards and project performance expected are much higher than those of most other guanaco management experiences in the country.

Each year, a temporary campsite is established before the round-up begins in an abandoned oil location in the base of Cerro El Loro (S36 $06^{\prime}$ W69 $09^{\prime}$ ), about 140-km away from the nearest settlement (Figure 2). The main activities by the Payún Matrú Cooperative associated with guanaco capture include (1) Installation of the camp. This requires installing a water tank with drinking water which is brought from the Malargüe city, and providing electric power generating equipment, radio transmitters and restrooms. (2) Building the capture structure and shearing corral. (3) Round-up, shearing and release of sheared guanacos. (4) Removal of all structures and cleaning the site after the shearing to reduce the environmental impact (Table 1).

Installing the camp, building the structures, doing the round-up and shearing are male tasks. However, during the events of capture and shearing the role of women is very important. As the guanaco round-up takes place at the same time as the goat parturition, many women remain at their homesteads and deal with the daily activities while their husbands and sons are capturing guanacos. During the shearing, women are grouped in cleaning the tables for the first de-hairing of the fibre, and are responsible for cooking for the whole camp. Beginning in 2007, women who were members of the Cooperative received training in order to perform tasks related to handmade processing of the fibre such as de-hairing, carding and spinning.

\section{Guanaco round-up}

Wild guanacos are captured by horseback riders driving them towards a trap (Figure 3). This trap has two V-shaped arms, followed by a pre-capture corral, a capture corral, three additional successive corrals, a holding pen and a finally a shearing corral (Figure 4). The arms of the trap are approximately $3500-\mathrm{m}$ long and their distal opening is approximately $1500 \mathrm{~m}$. To avoid escapes, the whole capture structure has a $2.5-\mathrm{m}$-high fence and the last 


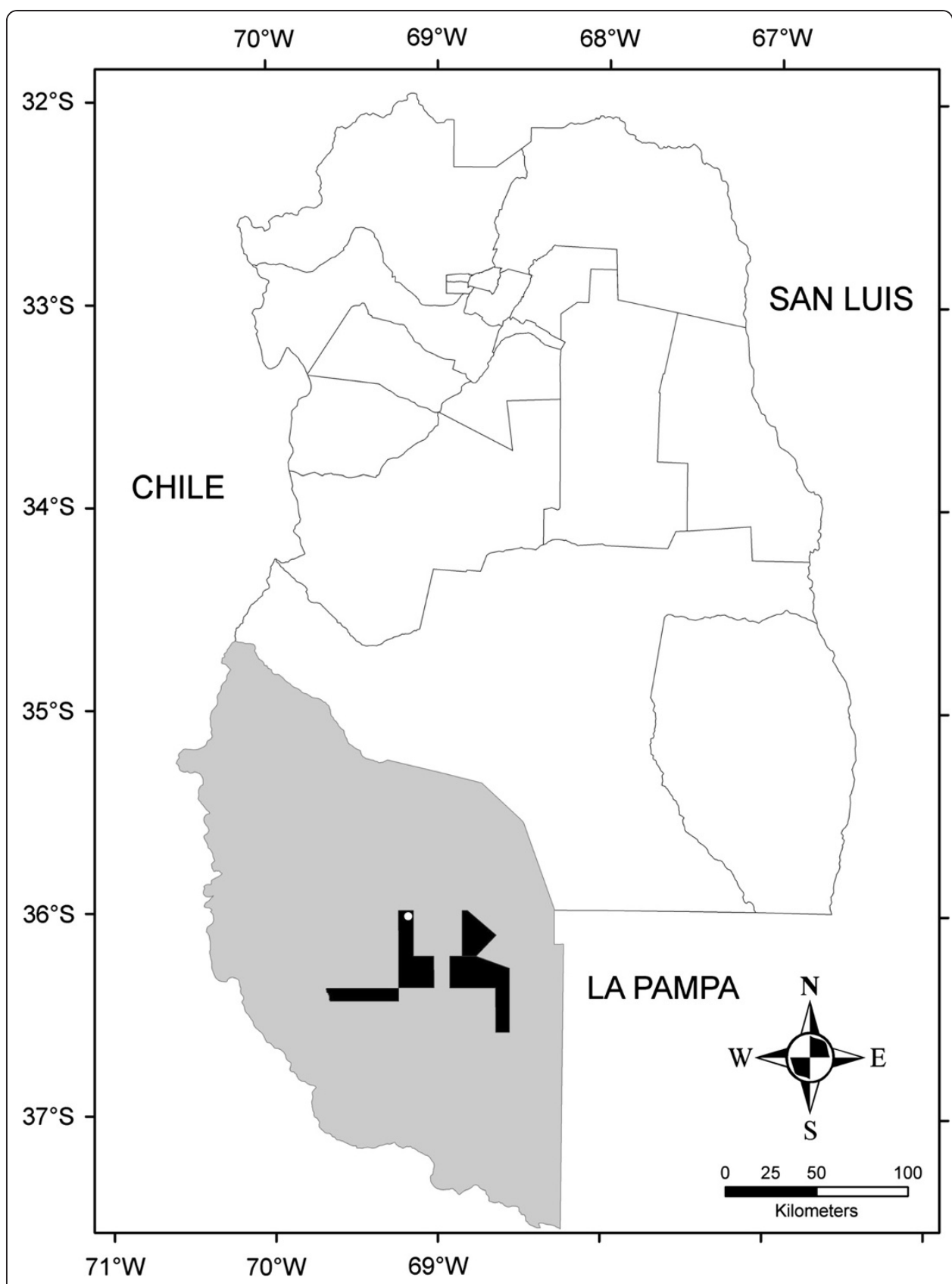

Figure 2 Malargüe Department (in grey) with La Payunia Provincial Reserve (in black). The guanaco management area inside the Reserve is shown with white dot.

Table 1 Activities involved in guanacos management

\begin{tabular}{lll}
\hline Activity & Number of workers & Days \\
\hline Camp installation & 4 & 2 \\
Build the capture structure and shear corral & 13 & 13 \\
Round-up and shearing & 24 & 4 \\
Removal of all structures & 6 & 3 \\
Cooking during the round-up & 3 & Every day
\end{tabular}




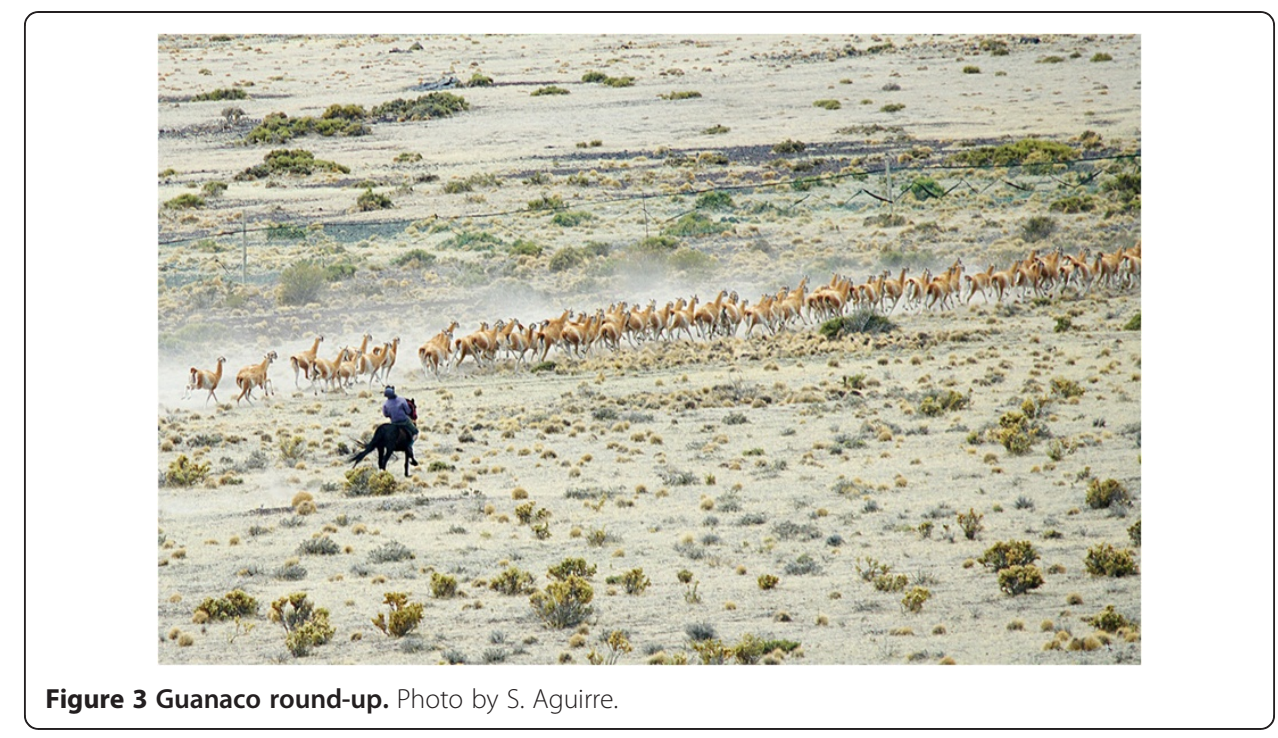

pen is also enclosed with shade nets. The walls of the three successive corrals are lined with carpet to prevent the guanacos seeing outside the corrals. The animals are removed from the holding pen, hooded to reduce visual stimulus, immobilized by binding their legs, then placed on a gurney and taken to the shearing machines. Shearing is carried out using an electric machine powered by a generator. The shorn individuals are sampled for biological studies, identified with numbered and coloured (according to sex) collars and then released. The animals are handled according to the "Good Practices of Wild Guanacos Handling Protocol" (Carmanchahi and Marull 2012). This protocol provides basic guidelines for the handling of guanacos in the interests of animal wellbeing, considering that guanacos are wild animals not accustomed to human contact.

\section{Fibre obtained}

Since the first guanaco round-up, in 2005, the number of guanacos captured has increased and the number of horse riders involved has decreased as captures became more efficient (Table 2). Working with a wild population of guanacos results in uncertainty in terms of productivity. For example, in 2010, there were less guanacos in the management area because of droughts which resulted in a decrease in the number of guanacos captured and the amount of fibre obtained.

The number of guanacos shorn per hour increased from 3 in 2005, to 16 in 2010, while the handling time per animal decreased from 25.5 to $7.6 \mathrm{~min}$ (Table 3).

Since the beginning of the project, 569 guanacos have been shorn, which resulted in $208.5 \mathrm{~kg}$ of guanaco fleece (Table 4). In 2009, the Cooperative decided to shear only the parts of the fleece lying on the backs and the flanks of the animals and leave untouched the white and underparts which are important for guanaco thermoregulation and which do not have a high market value (Figure 5). Fibre obtained had a diameter average of $15.8 \mu \mathrm{m}$, 36-mm length and $99.2 \%$ comfort factor. This latter is an indicator of the proportion of fibres less than $30 \mu \mathrm{m}$. When the comfort factor is less than $96 \%$, the fibre itches when in contact with human skin. 


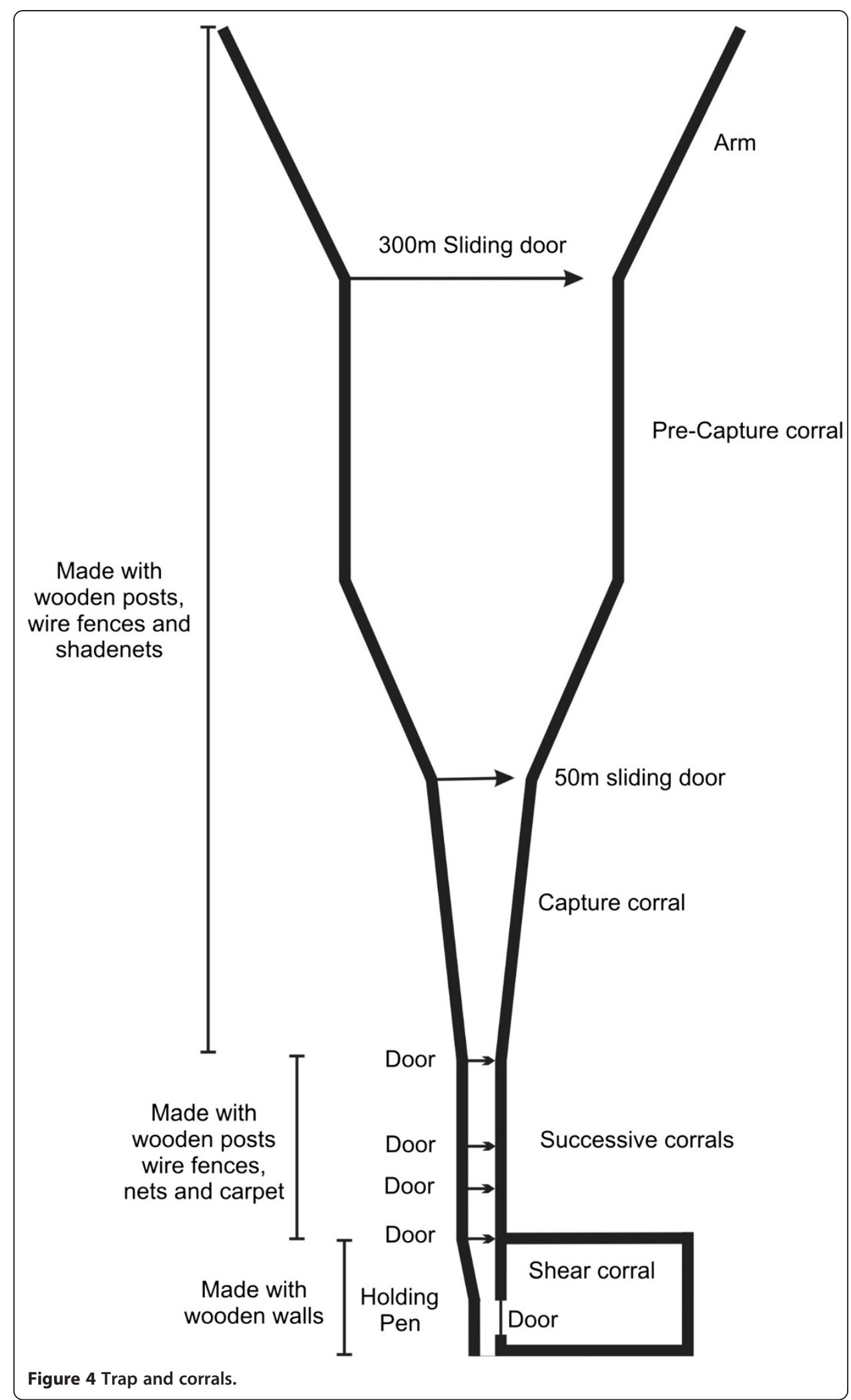


Table 2 Guanaco captures over the years

\begin{tabular}{lllll}
\hline Year & $\begin{array}{l}\text { Number of } \\
\text { captures events }\end{array}$ & $\begin{array}{l}\text { Number of } \\
\text { horse riders }\end{array}$ & $\begin{array}{l}\text { Number of } \\
\text { guanacos captured }\end{array}$ & $\begin{array}{l}\text { Number of } \\
\text { guanacos shorn }\end{array}$ \\
\hline 2005 & 3 & 40 & 14 & 14 \\
2006 & 2 & 20 & 155 & 154 \\
2007 & 2 & 30 & 100 & 88 \\
2009 & 2 & 25 & 239 & 210 \\
2010 & 3 & 10 & 148 & 103 \\
\hline
\end{tabular}

\section{Product commercialization}

The Payún Matrú Cooperative faces a number of challenges with regard to commercialization. The first (shared with private producers) is the lack of an established transparent market for guanaco fibre and a small overall market demand for guanaco processed goods (Lichtenstein 2011). The similarity between guanaco and vicuña fibre poses the need to develop easy methods to help authorities that control exports and imports to tell them apart to ensure that guanaco is commercialized as such.

As in the case of other pastoralists (Hatfield and Davies 2006), the Payún Matrú Cooperative faces constraints in realizing the economic potential of their system owing to high transaction costs, such as long distance to markets, processing plants or final consumers, absence of formal markets, poor access to information, lack of fair contracts, difficulties for marketing and creating distribution channels, limited access to credit facilities, lack of proper communication systems, excessive government bureaucracy, etc.

In 2009, the Cooperative made its first sale of handmade products (Figure 6). To date, the Cooperative has sold $61 \mathrm{~kg}$ of de-haired fibre at an average price of USD \$ $388 / \mathrm{kg}$ and $4 \mathrm{~kg}$ of yarn at an average of USD \$650/kg. The determination of Payún Matrú Cooperative members to sell processed goods instead of raw fibre had a cost in terms of foregone revenues over the first years of the project but enabled them to generate new sources of income, develop expertise in fibre spinning and create a unique niche for artisanal guanaco products.

\section{Future prospects}

Recent studies show that there are a high percentage of cashmere goats in the region that are undervalued. Currently, there are 700,000 goats within the Department Malargüe, of which approximately $25 \%$ are cashmere (Soto, personal communication, 2011). Samples of 60 producers in the study area averaged $250 \mathrm{~g}$ of cashmere per animal, with a fibre diameter between 15 and $19 \mu \mathrm{m}$. The Cooperative members are keen to diversify regional production and incorporate cashmere fibre in their portfolio. Extension and training tools need to be developed in order to improve cashmere production and capitalize on existing pastoral knowledge. Emphasizing cashmere would lead to the

Table 3 Efficiency of handling during shearing

\begin{tabular}{llllll}
\hline & $\mathbf{2 0 0 5}$ & $\mathbf{2 0 0 6}$ & $\mathbf{2 0 0 7}$ & $\mathbf{2 0 0 9}$ & $\mathbf{2 0 1 0}$ \\
\hline Retention time (min) & 25.5 & 7.8 & 8.8 & 6.4 & 7.6 \\
Sheared guanacos per hour & 3 & 11.5 & 11 & 15 & 16 \\
\hline
\end{tabular}


Table 4 Fibre production over the years

\begin{tabular}{llllll}
\hline Year & & Fleece $(\mathbf{k g})$ & White parts $(\mathbf{k g})$ & Discard $(\mathbf{k g})$ & Total $\mathbf{( k g )}$ \\
\hline 2005 & Total & 4.36 & 0.83 & 0.32 & 5.51 \\
& Average & 0.31 & 0.06 & 0.025 & 0.41 \\
2006 & Total & 50.64 & 12.85 & 14.67 & 78.16 \\
& Average & 0.33 & 0.08 & 0.095 & 0.51 \\
2007 & Total & 33.29 & 2.76 & 11.15 & 47.20 \\
& Average & 0.38 & 0.03 & 0.01 & 0.54 \\
2009 & Total & 80.16 & & & 80.16 \\
& Average & 0.38 & & & 0.38 \\
2010 & Total & 39.99 & & & 39.99 \\
& Average & 0.39 & & & 0.39 \\
\hline
\end{tabular}

Average refers to average production per individual.

selection of the goats with the finest fleece and highest market value which in turn would lead to a reduction in the total herd size because low-quality animals would not be favoured. Consequently, there would be a reduction in overgrazing.

\section{Conclusions}

This article presents a novel example of interaction between wildlife sustainable use and pastoralists in the Argentinean Andes. The case study illustrates how a conflict over the use of grassland between domestic livestock and a wild species could be turned into an opportunity for economic diversification for pastoralists. The Payún Matrú case study is quite unique. On one hand, this is the only example in Argentina where a low-income community (instead of ranch owners) benefits from guanaco use. This is also the first case where producers decide not to export raw material, but to generate added value instead and work towards the production of finished goods at the local level.

The collaboration between local people, scientists and international NGOs contributed towards the development of a project based on high animal welfare standards and scientific knowledge and mutual learning. Non-economic benefits such as community empowerment, capacity building, community integration and political visibility of

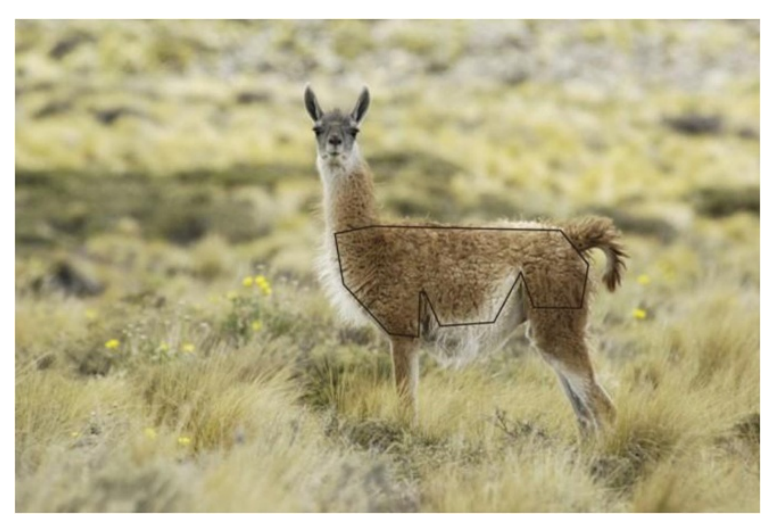

Figure 5 Photo showing a guanaco and the area of the fleece sheared. Photo by J. Maher. 


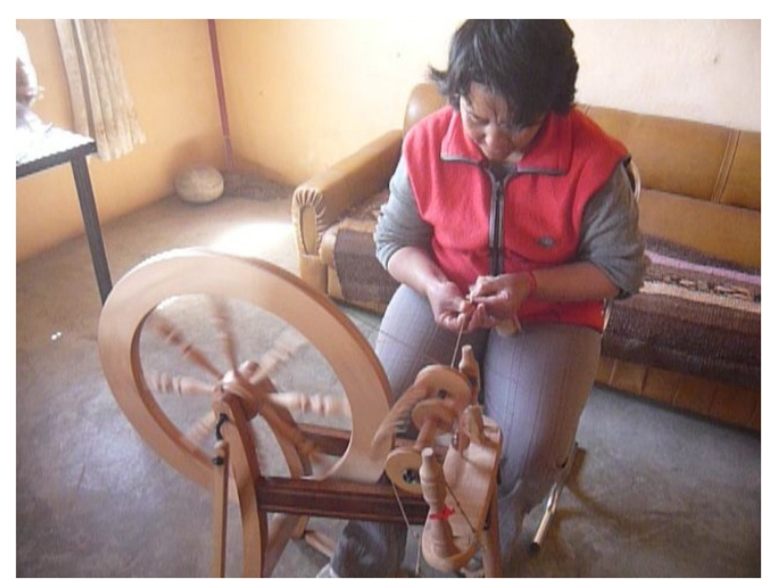

Figure 6 Ana, a cooperative member spinning guanaco fibre. Photo by G. Lichtenstein.

remote and forgotten pastoralists kept the project going through many hazards. The ability of the Cooperative to collaborate with multiple partners contributed towards the project resilience and created a safety net.

This project has the potential to be replicated either by other cooperatives on public land or by individual or grouped producers on private land. However, it is important to take into account some technical factors that contribute towards the feasibility of the experiences on top of the social capital of the Cooperative: (a) high guanaco densities during the months when shearing is permitted: (b) an easy topography and open vegetation to enable driving guanacos towards corrals; (c) good logistics (e.g. ease of access to capture site, availability of water, lack of fences dividing the area, etc.); (d) availability of funding for infrastructure and labour.

The creation of a transparent market for guanaco fibre and it's by-products remains as a challenge, as well as the development of a Fair Trade scheme and the diversification of products and markets.

\section{Methods}

This article is based on fieldwork conducted in La Payunia Provincial Reserve, located in the Malargüe Department, in the South of the Mendoza province, Argentina. Fieldwork was conducted along the period 2005 to 2010. The project background and its socio-economic impact were gathered by semi-structured interviews with Cooperative members and the stakeholders related to the project (e.g. provincial Director of Fauna, NGOs, technicians, etc.). The description of the management system, capture and harvesting resulted from participant observation in 12 individual guanaco round-up events during the period of study. Fibre production data resulted from the official reports by the Provincial Department of Renewable Natural Resources. Fibre was classified using the commercial denomination as down, white parts and discard. Down has the highest commercial value. Fibre characteristics such as diameter, length and comfort factor were determined by the Textile Research and Development Centre from the Argentine National Institute of Industrial Technology (INTI). Data on fibre commercialization were provided by the Cooperative. 


\section{Appendix}

We use the definition of desertification adopted by the UN Convention to Combat Desertification as defined by UNEP and modified by UNCED. According to this, "desertification is land degradation in arid, semi-arid and dry sub-humid areas resulting from various factors, including climatic variations and human activities". The Convention adds that desertification is caused by complex interactions among physical, biological, social, cultural and economic factors.

\section{Competing interests}

The authors declare that they have no competing interests.

\section{Authors' contributions}

PC gathered the data on guanaco handling and fibre production during the captures. GL did participant observation during captures and interviewed Cooperative members and various stakeholders. PC and GL worked on the analysis and interpretation of data. Both authors have been involved in drafting the manuscript and revising it critically for important intellectual content. Both authors read and approved the final manuscript.

\section{Authors' information}

Dr. Gabriela Lichtenstein is the Chair of IUCN's South American Camelid Specialist Group (GECS). She holds a Permanent Research Position at the National Research Council (CONICET), and teaches at the University of Buenos Aires. Her research interests include the links between poverty alleviation and conservation, commodity chain analysis for wild South American camelid fibre and the establishment of trade links to help the delivery of a fairer and more equitable proportion of benefits to local people. Dr. Pablo Carmanchahi is a researcher at CONICET and a technical advisor to the wild management and conservation programme in La Payunia Provincial Reserve. He researches the eco-physiological and population consequences of guanaco management, and develops sustainable alternatives for arid-land production. Dr. Carmanchahi is a member of IUCN's South American Camelid Specialist Group.

\section{Acknowledgements}

GL received financial assistance from the University of Buenos Aires (UBACYT G010) and CONICET (PIP 0110). Both authors wish to thank the Cooperative Payún Matrú for sharing their data, Carl Mundt for editorial revisions and two anonymous referees for their valuable comments.

\section{Author details}

${ }^{1}$ Instituto Nacional de Antropología y Pensamiento Latinoamericano (INAPL), CONICET, 3 de Febrero 1378, 1426 Buenos Aires, Argentina. ${ }^{2}$ Grupo de Investigaciones en Ecofisiología de Fauna Silvestre (GIEFAS), INIBIOMA - CONICET Asentamiento Universitario San Martin de los Andes, Universidad Nacional del Comahue, Pasaje de la Paz 235, (8370), Neuquén, Argentina.

Received: 31 October 2011 Accepted: 26 January 2012

Published: 28 September 2012

\section{References}

Aagensen, D. 2000. Crisis conservation at the end of the world: Sheep ranching in Argentine Patagonia. Environ Conserv 27: $208-215$.

Baldi, R., A. Novaro, S. Walker, M. Funes, P. Ferrando, M. Failla, and P. Carmanchahi. 2010. Guanaco management in Patagonian rangelands: A conservation opportunity on the brink of collapse. In Wild rangelands: Conserving wildlife while maintaining livestock in semi-arid ecosystem, ed. J. du Toit, R. Kock, and J. Deutsch, 266-290. Oxford: Wiley-Blackwell Publishing.

Bandieri, S., O. Favaroy, and M. Morinelli. 1993. Historia de Neuquén. Buenos Aires: Plus Ultra Press.

Bendini, M., M.B. Alvaro, and N.G. Steimbreger. 2010. Agricultura y proyectificación en Argentina. Studies in Political Science 2: 1-93.

Candia, R., S. Puig, A. Dalmasso, F. Videla, and E.M. Carretero. 1993. Diseño del plan de manejo para la Reserva Provincial La Payunia (Malargüe, Mendoza). Multequina 2: 5-87.

Carmanchahi, P. and C. Marull. 2012. Protocolo de Buenas Prácticas de Manejo de Guanacos (Lama guanicoe) Silvestres. South American Camelid Specialist Group (GECS). International Union for the Conservation of Nature (IUCN). http://www.camelidosgecs.com.ar/pdf/ba_guanacos_2012.pdf. Accessed 28 July 2012.

FAO. 1992. Estrategias para el Manejo y Aprovechamiento Racional del Guanacos (Lama guanicoe). Documento Técnico N 9. Oficina Regional de la FAO para América Latina y el Caribe. Proyecto FAO/PNUMA sobre manejo de áreas silvestres, áreas protegidas y vida silvestre en América Latina y el Caribe. Santiago de Chile: FAO/PNUMA.

Fernández, J. 2004. Diagnóstico sociodemográfico de la Reserva La Payunia. Dirección de Recursos Naturales Renovables de Mendoza. Unpublished Technical Report 25pp.

Hatfield, R. and J. Davies. 2006. Global review of the economics of pastoralism. World Imitative for Sustainable Pastoralism. http://cmsdata.iucn.org/downloads/global_review_ofthe_economicsof_pastoralism_en.pdf. Accessed 28 Oct 2011.

Lanari, M.R. 2004. Variación y diferenciación genética y fenotípica de la Cabra Criolla Neuquina en relación con su sistema rural campesino, 234 p. University Nacional del Comahue: Doctoral thesis. Centro Regional Universitario Bariloche.

Lichtenstein, G. 2011. Use of Vicuñas (Vicugna vicugna) and Guanacos (Lama guanicoe) in Andean countries: Linking community-based conservation initiatives with international markets. In In CITES and CBNRM, Proceedings of an 
international symposium on "The relevance of CBNRM to the conservation and sustainable use of CITES-listed species in exporting countries", ed. Abensperg-Traun Max, Roe Dilys, and O'Criodain Colman, 103-108. Gland: IUCN; and London: IIED.

Macario, J., P. Dayenoff, A. Orozco, and M.P. Diez. 2007. Proyecto de desarrollo caprino en Malargüe. V Congreso de Especialistas en Pequeños Rumiantes y Camélidos Sudamericanos, Mendoza, Argentina. http://www.produccion-animal. com.ar/produccion_caprina/produccion_caprina/82-Macario.pdf. Accessed 28 Oct 2011.

Martínez Carretero, E. 2004. Provincia fitogeográfica de la Payunia. Boletín de la Sociedad Argentina de Botánica $39:$ 195-223.

Naumann, M., and M. Madariaga. 2003. Atlas Argentino, Programa de Acción Nacional de Lucha contra la Desertificación. Buenos Aires: Secretaría de Ambiente y Desarrollo Sustentable, Instituto Nacional de Tecnología Agropecuaria.

Nori, M., A. Crawford, and J. Switzer. 2005. Herding on the Brink. Towards a global survey of pastoral communities and conflict. IISD. http://www.iisd.org/pdf/2005/security_herding_on_brink.pdf. Accessed 28 Oct 2011.

Novaro, A., M. Funes, and S. Walker. 2000. Ecological extinction of native prey of a carnivore assemblage in Argentine Patagonia. Biol Conserv 92: 25-33.

Paruelo J, M., G.A. Golluscio, EG. Jobbágy, M. Canevari, and M.R. Aguiar. 2006. Situacion Ambiental en la Estepa Patagonica. In La situación ambiental Argentina 2005, ed. A. Brown, U. Martinez Ortiz, M. Acerbi, and J. Corcuera, 303-320. Buenos Aires: Fundacion Vida Silvestre.

Puig, S. 1995. Técnicas para el Manejo del Guanaco. Gland: UICN/CSE Ed.

Puig, S., G. Ferraris, M. Superina, and F. Videla. 2003. Distribución de densidades de guanacos (Lama guanicoe) en el norte de la reserva La Payunia y su área de influencia (Mendoza, Argentina). Multequina 12: 37-48.

Quispe, E., T. Rodríguez, L. Iñiguez, and J. Mueller. 2009. Producción de fibra de alpaca, llama, vicuña y guanaco en Sudamérica. Animal Genetic Resources Information 45: 1-14

Von, Thüngen, J. and M.R. Lanari. 2010. Profitability of sheep farming and wildlife management in Patagonia. Pastoralism 1(2): 274-290.

Westreicher, C.A., J.L. Mérega, and G. Palmili. 2007. The economics of pastoralism: Study on current practices in South America. Nomadic Peoples 11(2): 87-105.

doi:10.1186/2041-7136-2-16

Cite this article as: Lichtenstein and Carmanchahi: Guanaco management by pastoralists in the Southern Andes. Pastoralism: Research, Policy and Practice 2012 2:16.

Submit your manuscript to a SpringerOpen ${ }^{\circ}$ journal and benefit from:

- Convenient online submission

- Rigorous peer review

- Immediate publication on acceptance

- Open access: articles freely available online

- High visibility within the field

- Retaining the copyright to your article

Submit your next manuscript at $>$ springeropen.com 